Abstracta Iranica Iranica

Revue bibliographique pour le domaine irano-aryen

Volume 26 | 2005

Comptes rendus des publications de 2003

\title{
« Vāže-gozīnī va esteqlāl-e zabān-e fārsī ». Našr-e Dāneš, 20, 1 (1382/2003), pp. 2 -7.
}

\section{Charles-Henri de Fouchécour}

\section{Q OpenEdition \\ 12 Journals}

Édition électronique

URL : http://journals.openedition.org/abstractairanica/3685

ISSN : 1961-960X

\section{Éditeur :}

CNRS (UMR 7528 Mondes iraniens et indiens), Éditions de l'IFRI

\section{Édition imprimée}

Date de publication : 15 mai 2005

ISSN : 0240-8910

\section{Référence électronique}

Charles-Henri de Fouchécour, « « Vāže-gozīini va esteqlāl-e zabān-e fārsī ». Našr-e Dāneš, 20, 1

(1382/2003), pp. 2 -7. », Abstracta Iranica [En ligne], Volume 26 | 2005, document 45, mis en ligne le 15 décembre 2005, consulté le 25 septembre 2020. URL : http://journals.openedition.org/

abstractairanica/3685

Ce document a été généré automatiquement le 25 septembre 2020.

Tous droits réservés 


\title{
«Vāže-gozīnī va esteqlāl-e zabān-e fārsī ». Našr-e Dāneš, 20, 1 (1382/2003), pp. $2-7$.
}

\author{
Charles-Henri de Fouchécour
}

1 Réflexions pertinentes sur l'évolution contemporaine de la langue persane. Longtemps langue régulée par des savants bilingues, elle utilisa comme l'on sait l'arabe de son temps, et elle a conservé cet arabe qui, lexicalement, n'est plus en plusieurs occasions l'arabe du $20^{\mathrm{e}} \mathrm{s}$. Mais longtemps aussi langue des poètes, elle fournit abondamment jusqu'à aujourd'hui tous les éléments persans voulus pour la formation de mots nouveaux, éliminant ainsi du persan les éléments arabes obsolètes. L'A. montre tout ce qu'a eu de positif l'œuvre de l'Académie de la Langue et de la Culture Persanes (Farhangestān-e zabān va adab-e fārsī) et constate que les efforts faits portent leurs fruits ; la prise de distance est définitive à l'égard de la part de la morphologie inspirée de l'arabe : la grammaire persane contemporaine est souveraine dans la construction de mots nouveaux. L'A. montre combien ce Farhangestān, dans sa troisième phase historique, a su ancrer définitivement la pratique d'une construction de mots nouveaux grâce à la composition d'éléments proprement persans, comme le font en particulier les langues scientifiques occidentales par leur recours aux éléments morphologiques tirés du grec et du latin. En comparant l'évolution des langues européennes dans leur continuité avec celle du persan, on voit que le danger pour celle-ci est d'en arriver à créer une langue artificielle. Ce point est bien souligné par l'A., qui propose quelques règles qui doivent parer à ce danger, en particulier celle de considérer que le persan a toujours su emprunter des mots étrangers et ne doit pas y répugner. A charge à l'Académie de délimiter les conditions d'admission en persan des mots étrangers sans équivalence possible en persan. Un bon article de bilan et de prospective. 
INDEX

Thèmes : 2.2. Langues vivantes et dialectes

Mots-clés : linguistique, langue persane, persan contemporain

Keywords : linguistics, Persian language, contemporary Persian

\section{AUTEURS}

CHARLES-HENRI DE FOUCHÉCOUR

Fondateur de la revue Abstracta Iranica - Paris 